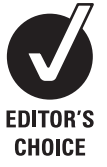
Centre for Altitude, Space and
Extreme Environment Medicine (CASE Medicine), University College London, Institute of Human Health and Performance, London N19 5LW, UK

Correspondence to: Dr D Martin, Centre for Altitude, Space and Extreme Environment Medicine (CASE Medicine), University College London, Institute of Human Health and Performance, First Floor, Charterhouse Building, Archway Campus, Highgate Hill, London N19 5LW, UK; dan.s.martin@ gmail.com

Received 8 July 2008 Accepted 26 September 2008

\title{
From mountain to bedside: understanding the clinical relevance of human acclimatisation to high-altitude hypoxia
}

\author{
D Martin, J Windsor
}

\section{ABSTRACT}

For centuries man has strived to reach the greatest heights on earth. In order to explain the physiological changes that are needed to achieve this, physiologists have tended to focus on the improvements made in oxygen delivery to the body's tissues. Although this explains much of the acclimatisation process, it has not been able to address the large interindividual variations seen in human performance at altitude. In recent years, attention has shifted and now focuses on microvascular and cellular responses in an attempt to explain these differences. Investigating these processes not only helps to unravel the process of acclimatising to altitude, but it may also improve our understanding of the body's response to hypoxia in those with critical illness.

\begin{abstract}
Lack of oxygen dulls the mind and judgement, slows the reflexes, weakens the muscles, and takes away our higher faculties. The higher one goes, the more serious are these effects. Too many people forget this exactly at a time when they should be most responsive to the danger.
\end{abstract}

The World Health Organization estimates that approximately 35 million people travel to altitudes above $3000 \mathrm{~m}$ each year. ${ }^{2}$ Although this presents a variety of physical hardships, the single greatest challenge faced is the fall in barometric pressure and the resulting decline in the partial pressure of oxygen. With time, humans can adapt to this harsh environment via a process known as acclimatisation. This review aims to summarise our understanding of the acclimatisation process to date by focusing on well-recognised mechanisms before going on to discuss new concepts in this field. By studying the way the human body responds to high altitude, we may also improve our understanding of the way hypoxia affects patients.

\section{ACCLIMATISATION TO ALTITUDE}

Hypobaric hypoxia leads to a fall in the inspired partial pressure of oxygen $\left(\mathrm{PIO}_{2}\right)$, which, in the absence of adaptive mechanisms, lowers alveolar partial pressure of oxygen $\left(\mathrm{PAO}_{2}\right)$, and results in a reduction in the driving pressure needed for the diffusion of oxygen across the alveolar-capillary barrier. The result of these changes is a fall in both the arterial partial pressure of oxygen $\left(\mathrm{PaO}_{2}\right)$ and the arterial oxygen saturation $\left(\mathrm{SaO}_{2}\right)$, leading to a reduction in oxygen delivered to the tissues and the potential for cellular hypoxia and organ dysfunction.

A successful period of acclimatisation at high altitude ensures that humans are able to function in a similar way to that seen at sea level. Historically, we have understood this to involve restoring sea-level values of oxygen delivered to the body's tissues. Oxygen delivery $\left(\mathrm{DO}_{2}\right)$ is defined as the product of cardiac output (Q) and arterial oxygen content $\left(\mathrm{CaO}_{2}\right)$ (table 1). Here, $\mathrm{Q}$ is the product of heart rate and stroke volume and $\mathrm{CaO}_{2}$ is the sum of the oxygen bound to haemoglobin and that dissolved in the plasma. On ascent to altitude, $\mathrm{CaO}_{2}$ falls and $\mathrm{DO}_{2}$ is therefore reduced. In order to counteract this, three principal physiological changes occur as part of the acclimatisation process: (1) $\mathrm{O}$ is increased; (2) $\mathrm{SaO}_{2}$ is restored; (3) haemoglobin concentration is increased.

\section{(1) Increased 0}

Within minutes of ascending to altitude, increases during both rest and submaximal exercise. This was first observed in resting volunteers by the physiologists C G Douglas and J S Haldane during their ground-breaking experiments on Pike's Peak (4300 m) in 1911. ${ }^{3}$ On the same mountain, some 60 years later, researchers were able to confirm that $\mathrm{Q}$ was also raised for a given level of submaximal exercise. Using three different work settings on a cycle ergometer, the team showed a $10-15 \%$ increase in $\mathrm{Q}$ during exercise in the first 4 days at altitude. ${ }^{4}$ However, subsequent studies have shown that this increase is short lived, and $\mathrm{Q}$ during rest and submaximal exercise returns to sealevel values within a few weeks. ${ }^{5}$ Interestingly, the contributions made by the heart rate and stroke volume differ dramatically during this time. In a review of 11 studies looking at the effect of altitude on the cardiovascular system, Wolfel and Levine identified a $14-25 \%$ increase in heart rate and an 8 $32 \%$ fall in stroke volume during the first 4 weeks at $3800 \mathrm{~m}$ or higher. Although an increase in sympathetic activity can largely explain the persistent rise in heart rate, the reasons for a decline in stroke volume are poorly understood. This is particularly confusing because stroke volume does not return to normal values when the circulating volume is artificially restored to normal sea-level values. ${ }^{7}$ However, as we will see later, the process of acclimatisation is a dynamic one, and the contribution made by the cardiovascular system may only be required during initial exposure to altitude.

\section{(2) Restoration of $\mathrm{SaO}_{2}$}

Once oxygen molecules enter the body, they encounter a number of obstacles before they finally reach the mitochondria for which they are destined. 
At each of these obstacles, there is a step-like reduction in the partial pressure of the oxygen. This is commonly referred to as the "oxygen cascade" and was first described at altitude by the pioneering physiologist Joseph Barcroft more than 80 years ago. ${ }^{8}$ The profound effect that altitude has on the oxygen cascade can be seen in fig 1 using data from a simulated high-altitude ascent of Mount Everest. ${ }^{9}$ Although most of the steps in the oxygen cascade are beyond human control, the body can limit the fall in $\mathrm{PO}_{2}$ in one key area. As oxygen enters the alveoli, the $\mathrm{PO}_{2}$ falls as a result of the addition of the uptake of oxygen by the incoming mixed venous blood. $\mathrm{PAO}_{2}$ can be calculated from the alveolar gas equation:

$\mathrm{PAO}_{2}=\mathrm{PIO}_{2}-\left(\mathrm{PACO}_{2} / \mathrm{R}\right)$

where $\mathrm{R}$ is the respiratory exchange ratio (the ratio of the volume of carbon dioxide produced by the tissues to the volume of oxygen consumed per unit time, which varies with the substrate being used, eg, 0.7 for fat and 1.0 for glucose). According to this equation, if $\mathrm{R}$ remains unchanged, any reduction in $\mathrm{PACO}_{2}$ leads to an increase in $\mathrm{PAO}_{2}$. As ventilation and $\mathrm{PACO}_{2}$ are inversely proportional, any increase in the rate or depth of breathing will therefore result in a fall in $\mathrm{PACO}_{2}$ and an increase in $\mathrm{PAO}_{2}$.

Over the course of several days at altitude, ventilation increases involuntarily and results in a reduction in $\mathrm{PACO}_{2}$. This is largely due to the combined effects of two physiological responses: the hypoxic ventilatory response and the hypercapnic ventilatory response. ${ }^{10}$ As $\mathrm{PAO}_{2}$ falls, peripheral chemoreceptors in the carotid and aortic bodies are stimulated, causing ventilation to increase. This is known as the hypoxic ventilatory response, and the magnitude of the response varies widely between individuals. ${ }^{11}$ At sea level, any rise in ventilation lowers $\mathrm{PACO}_{2}$ and results in the slowing of breathing and an increase in $\mathrm{PACO}_{2}$. However, at altitude, the response from the central medullary chemoreceptors increases, triggering high levels of ventilation and a rise in $\mathrm{PAO}_{2} \cdot{ }^{12}$ This response, commonly referred to as the hypercapnic ventilatory response, is thought to be due largely to the reduction in bicarbonate ions $\left(\mathrm{HCO}_{3}{ }^{-}\right)$ that is commonly seen in the cerebrospinal fluid on ascent to altitude. ${ }^{13}$ The fall in $\mathrm{HCO}_{3}{ }^{-}$is the result of renal tubular cells failing to reabsorb $\mathrm{HCO}_{3}{ }^{-}$and results in acidic cerebrospinal fluid, which encourages higher levels of ventilation. ${ }^{14}$

These changes result in an increase in $\mathrm{PaO}_{2}$ and a substantial rise in $\mathrm{SaO}_{2}$ due to the steep slope of the oxygen-haemoglobin dissociation curve over the range of $\mathrm{PaO}_{2}$ values seen at altitude. The rapid nature of ventilatory acclimatisation allows time for slower changes in the haematological system to occur.

\section{(3) Increased haemoglobin concentration}

Alongside the changes seen in $\mathrm{Q}$ and $\mathrm{SaO}_{2}$, the acclimatisation process also results in an increase in the concentration of circulating haemoglobin. This is a result of two processes.

Table 1 Formulae for the calculation of systemic oxygen delivery

\begin{tabular}{ll}
\hline Calculation of oxygen delivery $\left(\mathrm{Do}_{2}\right)$ & Example in a $70 \mathrm{~kg} \mathrm{man}$ \\
\hline $\mathrm{Do}_{2}=0 \times \mathrm{CaO}_{2}$ & $\mathrm{Do}_{2}=4.9 \times 194=950.6 \mathrm{ml} / \mathrm{min}$ \\
$\mathrm{O}=\mathrm{HR} \times \mathrm{SV}$ & $\mathrm{O}=70 \times 70=4.9 \mathrm{l} / \mathrm{min}$ \\
$\mathrm{CaO}_{2}=\left([\mathrm{Hb}] \times \mathrm{SaO}_{2} \times \mathrm{H}\right)+\left(\mathrm{PaO}_{2} \times \mathrm{S}\right)$ & $\mathrm{CaO}_{2}=(14.0 \times .98 \times 1.39)+(13.3 \times 0.0225)$ \\
& $=19.1+0.3$ \\
& $=19.4 \mathrm{ml} \mathrm{O}_{2} / 100 \mathrm{ml}$ blood \\
& $=194 \mathrm{ml} 0_{2} / 1$
\end{tabular}

$\mathrm{CaO}_{2}$, arterial oxygen content; $\mathrm{H}$, Hufners constant (1.39); [Hb], haemoglobin concentration; HR, heart rate; $\mathrm{PaO}_{2}$, arterial partial pressure of oxygen; $\mathrm{Q}$, cardiac output; $\mathrm{S}$, solubility coefficient of oxygen $(0.0225) ; \mathrm{SaO}_{2}$, arterial oxygen saturation of haemoglobin; SV, stroke volume. a. Arrival at altitude coincides with a rapid fall in plasma volume. Over several days, healthy individuals experience a fall by up to $20 \%$ in their plasma volume because water is excreted as urine or instead shifts into either the interstitium or cells. This results in a rapid increase in the concentration of circulating haemoglobin and subsequent rises in $\mathrm{CaO}_{2}$ and $\mathrm{DO}_{2} \cdot{ }^{15}$ Although this process can persist for several weeks, over a prolonged stay at altitude, plasma volume slowly returns to normal. After 18 weeks above $4000 \mathrm{~m}$, Pugh ${ }^{16}$ found that plasma volume had fallen by $21 \%$; however, 3 months later the difference was only $10 \%$.

b. Within minutes of arrival at altitude, increased cellular concentrations of the protein, hypoxia inducible factor $1 \alpha$ $(\mathrm{HIF} 1 \alpha)$, stimulate the release of erythropoietin from the liver and kidney. ${ }^{17}$ Erythropoietin subsequently binds to erythroid cell lines in the bone marrow, triggering the release of immature nucleated red blood cells (reticulocytes) into the circulation. In some cases, this can lead to a doubling in the number of circulating reticulocytes within 7 days of arrival at altitude. ${ }^{18}$ Although the plasma concentration of erythropoietin tends to fall over the course of 3 weeks at altitude, red cell production remains raised for up to 8 months in those new to altitude and can result in a $50 \%$ increase in red cell mass. ${ }^{19}$

\section{Changes in capillary density and mitochondrial volume and function at altitude}

There was a revelation in our understanding of human adaptation to hypoxia when the accepted hypotheses of changes in skeletal muscle capillary and mitochondrial density after chronic exposure to hypoxia were questioned.

Historically, it was believed that a sustained reduction in oxygen availability would lead to increases in capillary density and aerobic metabolic activity in order to restore cellular energy requirements. ${ }^{20}$ However, early studies of capillary density, on which these ideas were grounded, failed to take into account the dramatic decrease in muscle fibre cross-sectional area and skeletal muscle mass. ${ }^{21} 22$ Although overall capillary density appeared to increase, the capillary to fibre ratio remained unchanged. Thus the apparent rise in capillary density simply represented the reduction in muscle cross-sectional area. ${ }^{23}$

Traditional ideas were questioned further when skeletal muscle biopsy specimens taken from climbers returning from the Himalayas revealed a $30 \%$ reduction in mitochondrial volume density. ${ }^{21}$ In the same group of subjects, the activity of citrate synthase and cytochrome oxidase enzymes located within the mitochondria were reduced by $\sim 20 \%{ }^{24}$ As these two enzymes are involved in the citric acid cycle and oxidative phosphorylation, respectively, this would result in reduced oxidative capacity after prolonged exposure to hypoxia, which has been further confirmed in other studies. ${ }^{22} 25$ This combined body of evidence opposes preceding theories and suggests that muscle capillarity is increased, whereas cellular aerobic capacity and mitochondrial volume density are both reduced at altitude.

\section{SHORTCOMINGS OF THE CLASSICAL ACCLIMATISATION EXPLANATION}

The classical explanation of acclimatisation to moderate altitude has evolved over many years through description of physiological processes operating synergistically to increase oxygen flux to cells when faced with environmental hypobaric hypoxia. So effective is this adaptation that $\mathrm{CaO}_{2}$ tends to surpass sea-level values in most lowland people after an adequate period of acclimatisation (fig 2). ${ }^{26}{ }^{27}$ However, it has 


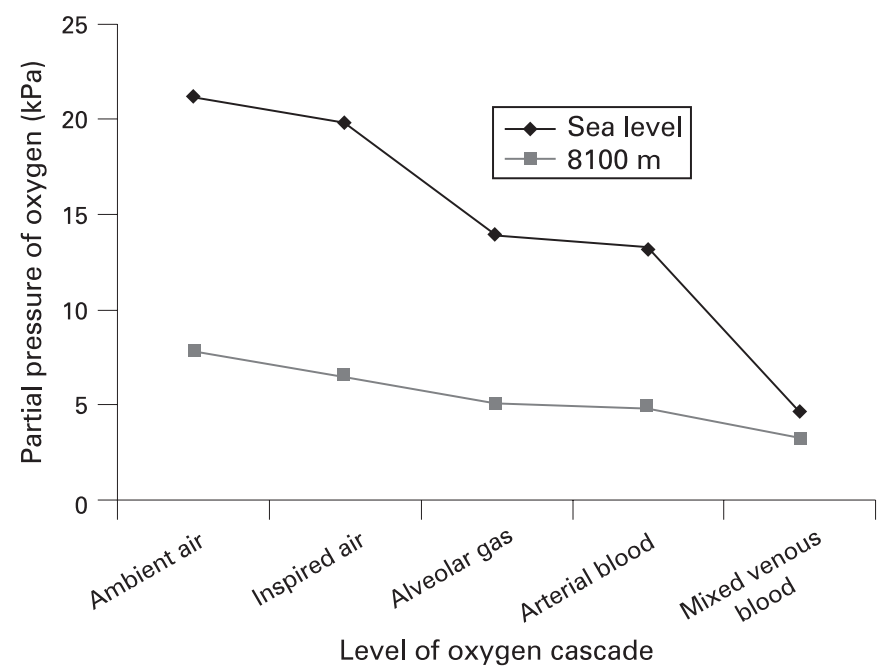

Figure 1 The oxygen cascade during rest at sea level and at an altitude of $8100 \mathrm{~m}$. Data taken from a simulated ascent of Mount Everest, Operation Everest II. ${ }^{9}$

become clear that, despite this remarkable adaptive phenomenon, exercise performance at altitude and susceptibility to altitude-related illnesses, such as acute mountain sickness, high altitude pulmonary oedema, and high altitude cerebral oedema, differs markedly between individuals. Our previous understanding of acclimatisation fails to explain these significant interindividual differences.

\section{High-altitude heroes are rarely athletes at sea level}

Interindividual variability in exercise performance at altitude is considerable. Accomplished high-altitude mountaineers are an example of those who adapt well to extreme degrees of hypoxia. Shortly after the first successful summit of Mount Everest by Reinhold Messner and Peter Habeler without the aid of supplemental oxygen, an investigation was performed with the aim of elucidating the traits that permit human survival at such heights. ${ }^{28}$ At sea level, Messner, Habeler and a number of their climbing colleagues were studied alongside a group of sedentary control subjects. Measures of aerobic performance, including static and dynamic lung volumes, echocardiography, skeletal muscle mitochondrial volume density and maximal oxygen consumption, were performed. With no significant differences noted between the two groups of subjects, the authors were forced to conclude that at sea level "elite highaltitude climbers do not have physiological adaptations to high altitude that justify their unique performance". ${ }^{28}$

\section{Sea-level performance fails to predict altitude performance}

Exceptional high-altitude athletes fail to display any remarkable physiological features at sea level, but those who cope poorly with hypobaric hypoxia are equally difficult to identify. ${ }^{29}$ No single test has the ability to differentiate those who fare well at altitude from those who do not. Early hypobaric chamber studies suggested an association between a blunted hypoxic ventilatory response and the development of acute mountain sickness. ${ }^{3031}$ However, these findings have not been confirmed in the field. ${ }^{32} 33$

Despite many decades of investigation, the only reliable indicator of well-being at altitude is a previous history of successful ascent to a similar elevation. This difficulty in predicting individual success or failure on exposure to hypoxia $\square$ Arterial partial pressure of oxygen

$\square$ Arterial oxygen saturation

$\square$ Haemoglobin concentration

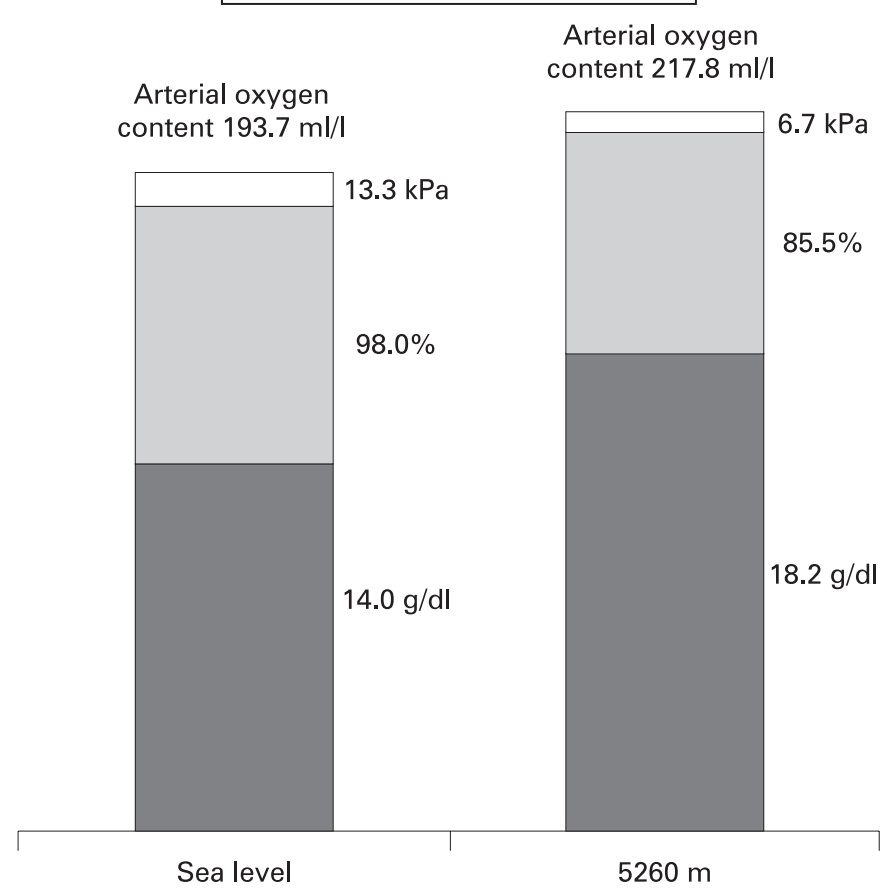

Figure 2 Change in arterial oxygen content after acclimatisation to $5260 \mathrm{~m}$. Arterial oxygen content at altitude calculated with figures taken from Calbet et al. ${ }^{26}$

is seen in clinical practice when managing hypoxic patients, particularly those categorised as critically ill. Despite advancements in medical technology and a clearer understanding of the pathophysiological processes underlying critical illness, clinicians still struggle to accurately differentiate survivors from non-survivors among a population of profoundly hypoxic patients.

\section{Exercise capacity remains limited after acclimatisation to high altitude}

Anyone who has travelled to high altitude will report that exercise is severely limited, and this has been well documented in reports over many centuries. ${ }^{34}$ As acclimatisation results in a return to sea-level values for systemic $\mathrm{Do}_{2}$, it is unclear why exercise capacity, measured by a reduction in maximum oxygen uptake $\left(\mathrm{VO}_{2} \mathrm{max}\right)$, remains significantly limited at altitude after adequate acclimatisation. ${ }^{9536}$ Acute exposure to hypoxia leads to a predictable reduction in $\mathrm{VO}_{2}$ max, which is proportional to the reduction in $\mathrm{CaO}_{2} \cdot{ }^{37}$ This direct relationship between $\mathrm{CaO}$ and $\mathrm{VO}_{2}$ max is lost after acclimatisation, suggesting that other processes are contributing to the exercise decrement. Debate over the underlying mechanism of this phenomenon has been ongoing for a number of decades. It has been suggested that the peripheral "microcirculation" may play an important role in the persistent limitation of exercise capacity at altitude. ${ }^{35}$ However, this distal component of the oxygen-transportation system has not been directly studied in lowland subjects ascending to altitude.

A recent study has compared the resting forearm blood flow of high-altitude-dwelling $(4200 \mathrm{~m})$ Tibetans and a group of lowland control subjects at sea level $(206 \mathrm{~m}) .{ }^{38}$ The forearm blood flow of the Tibetans was double that of the American 
comparison group and was associated with a $>10$-fold increase in circulating concentrations of bioactive nitric oxide products. ${ }^{38}$ Despite having lower systemic $\mathrm{CaO}_{2}$ than the American lowlanders, the Tibetans had higher regional levels of forearm $\mathrm{DO}_{2}$, perhaps because of increased peripheral generation of nitric oxide. This finding is beginning to draw attention away from central cardiorespiratory processes, and investigators are now starting to study the peripheral circulation to gain a better understanding of hypoxic adaptation.

\section{PROPOSED HYPOXIA SURVIVAL STRATEGIES}

Faced with a reduced availability of oxygen, humans must redress the supply-and-demand balance to avoid cellular dysfunction and death. The classic description of acclimatisation depends on a strategy of improving systemic $\mathrm{DO}_{2}$; other methods of restoring oxygen balance include reduced cellular oxygen consumption and improved efficiency of energy generation.

\section{Reduced cellular oxygen consumption}

In mammalian species, it is possible to reduce global oxygen consumption by lowering metabolic activity, as is commonly seen in hibernating animals and the developing fetus. At the cellular level, cells from anoxia-tolerant animals such as turtles show a reduction in metabolic rate of $\sim 25 \%$ after exposure to 30 min of anoxia. ${ }^{39}$ After the reintroduction of oxygen, this process is rapidly reversed. This anoxia-induced hypometabolic state is mainly brought about by downregulation of ATPconsuming membrane ion channels ${ }^{41}$ and permits neutral cellular energy balance during oxygen deprivation.

\section{Improved efficiency of energy production}

An alternative strategy for surviving prolonged and extreme hypoxia is a more efficient use of oxygen during the process of aerobic energy production. ${ }^{42}$ Although hard to imagine, the latter hypothesis has been demonstrated in isolated mitochondria in which oxidative phosphorylation became more efficient during exposure to hypoxia. ${ }^{43}$ This may explain the reduction in oxidative capacity described in climbers returning from a prolonged period at altitude. Alteration of uncoupling protein function may be one mechanism that facilitates improved efficiency of oxygen use during aerobic metabolism. Uncoupling proteins allow protons to re-enter the mitochondria in the final stages of oxidative phosphorylation, thereby bypassing ATP synthase and effectively generating an energy "leak". ${ }^{44}$ Finetuning of this energy leak in the cell's favour may permit improved metabolic efficiency.

\section{THE RELEVANCE OF HIGH-ALTITUDE PHYSIOLOGY TO CLINICAL MEDICINE}

The study of healthy volunteers ascending to altitude may help to define and improve our understanding of the limits of human tolerance to hypoxia. Hypoxaemia and cellular hypoxia are common in critically ill patients, but it is unclear whether these patients are able to adapt to hypoxia in a similar manner to those healthy individuals who acclimatise to altitude. Underlying pathology, infection and the development of critical illness in these patients may prevent a comparable acclimatisation process. Cellular mechanisms that determine systemic response to hypoxia are being unravelled at an incredible rate. Perhaps the most important of these in recent years has been the discovery of HIF1 $\alpha$ and its role in oxygen homoeostasis by regulation of multiple gene loci. ${ }^{45}{ }^{46}$ In the future, the role of
HIF1 $\alpha$ in the pathophysiology of cancer, mycocardial ischaemia and cerebral hypoxia may be manipulated beneficially. The role of HIF1 $\alpha$ in apoptosis and ischaemic preconditioning hold particularly exciting potential. ${ }^{47-49}$

High-altitude studies may suggest novel adaptive mechanisms in people who demonstrate tolerance to environmental hypoxia, leading to translational research in hypoxic patients. Climbers making a brief trip to great altitude mount an impressive polycythaemia in order to increase systemic oxygen flux. Tibetans, who have lived at altitude for countless generations, do not show this possibly counterproductive adaptation, but demonstrate marked changes in the peripheral circulation. ${ }^{38}$ In the latter situation, changes in the microcirculatory-mitochondrial unit may account for long-term hypoxic tolerance. Changes such as this may be mirrored in critical illness. ${ }^{50}$ Evidence suggests that, early in critical illness, restoration of normal levels of oxygen delivery is beneficial to outcome, ${ }^{51}$ whereas following the same line of management in established critical illness can be harmful to patients. ${ }^{52} 53$ These studies relied on measurements of systemic $\mathrm{DO}_{2}$, and their results may be explained by the fact that persistent disruption of the microcirculation is associated with poor outcome in septic critically ill patients. ${ }^{545}$ Furthermore, excessive use of oxygen may lead to inflammatory changes followed by irreversible damage in the pulmonary tract through the release of oxygen free radicals. ${ }^{56} 57$

Common themes between hypoxic critical illness and adaptation to the high-altitude environment are inspiring research into this field. Investigators are now looking beyond the oxygen flux process to explore the hypothesis that relative changes in oxygen consumption may explain differences in aerobic performance at altitude. ${ }^{58}$

\section{CONCLUSIONS}

Our understanding of how humans adapt to hypoxia at high altitude continues to develop. Over the last century, research has revealed changes in the cardiorespiratory and haematological systems that allow excursions to altitude through augmentation of systemic oxygen delivery. More recently, focus has turned to the peripheral microcirculation and the process of ATP production that occurs within the mitochondria. Although different arenas, high-altitude physiology and critical illness have interesting parallels which could be exploited in order to benefit hypoxic patients. Continuing work in the field of highaltitude medicine and physiology may help to unravel the complex mechanisms that underlie the reasons for survival in a hypoxic environment. The association of genetic markers with

\section{Key learning points}

- The classical explanation of acclimatisation to moderate altitude is restoration of systemic oxygen delivery.

- The reduced exercise capacity and marked interindividual variation in performance at altitude are difficult to explain in the face of normal systemic oxygen delivery.

- Changes in the peripheral microcirculation and mitochondrial enzymatic pathways may profoundly alter the balance between oxygen supply and demand at a cellular level on ascent to altitude.

- Lessons learnt from healthy volunteers exposed to the hypobaric hypoxia encountered at altitude may benefit patients with hypoxia resulting from disease. 


\section{Current research questions}

Do changes in the peripheral circulation affect the diffusion of oxygen into tissues at altitude?

- Do humans possess cellular strategies for coping with prolonged hypoxia?

- Will mechanisms that identify performance at high altitude translate into tools for predicting survival of hypoxia in the clinical setting?

beneficial adaptations in the microcirculatory-mitochondrial unit may one day provide clinicians with the tools that they require to accurately predict tolerance to hypoxia and therefore increase a patient's likelihood of survival.

\section{MULTIPLE CHOICE QUESTIONS (TRUE (T)/FALSE (F); ANSWERS AFTER THE REFERENCES)}

\section{After 1 week at altitude, the following physiological} parameters have returned to normal:
(A) Heart rate
(B) Stroke volume
(C) Cardiac output
(D) Amount of bicarbonate excreted in the urine
(E) Plasma volume

\section{On return from an expedition to the Himalayas:}

(A) Mitochondrial volume density in skeletal muscle is decreased

(B) Cellular aerobic capacity is increased

(C) Capillary density is increased in skeletal muscle

(D) Haemoglobin concentration remains raised for several months

(E) Heart rate and stroke volume rapidly return to normal

\section{The following increase within hours of ascending to altitude:}

(A) Serum concentrations of hypoxia-inducible factor and erythropoietin

(B) Sympathetic outflow

(C) Plasma volume

(D) Heart rate and cardiac output

(E) Red cell production

\section{On ascent to altitude, the following increase:}
(A) Barometric pressure
(B) Fraction of inspired oxygen
(C) Partial pressure of inspired oxygen
(D) Saturated vapour pressure of water
(E) Partial pressure of alveolar carbon dioxide

\section{The following physiological processes increase the partial pressure of alveolar oxygen:}

(A) An increase in respiratory rate and tidal volume

(B) A high-carbohydrate diet

(C) The use of supplemental oxygen

(D) A decrease in plasma volume

(E) An increase in the concentration of circulating haemoglobin

Competing interests: None.

\section{REFERENCES}

1. Houston CS. What price a summit? Wilderness Environ Med 1996;7:287-8.

2. Dumont L, Lysakowski C, Tramer MR, et al. Controversies in altitude medicine. Travel Med Infect Dis 2005;3:183-8.

3. Douglas CG, Haldane JS. The regulation of the general circulation rate in man. $J$ Physiol 1922;56:69-100

4. Vogel JA, Hansen JE, Harris CW. Cardiovascular responses in man during exhaustive work at sea level and high altitude. J Appl Physiol 1967:23:531-9.

5. Vogel JA, Harris CW. Cardiopulmonary responses of resting man during early exposure to high altitude. J Appl Physiol 1967;22:1124-8

6. Wolfel EE, Levine BD. The cardiovascular system at high altitude. In: Hornbein TF, Schoene RB, eds. High altitude: an exploration of human adaptation. New York: Marcel Dekker, 2001.

7. Calbet JA, Radegran G, Boushel R, et al. Plasma volume expansion does not increase maximal cardiac output or $\mathrm{VO}_{2}$ max in lowlanders acclimatized to altitude. Am J Physiol Heart Circ Physiol 2004;287:H1214-24.

8. Barcroft J. The respiratory function of blood: lessons from high altitude. Cambridge: Cambridge University Press, 1925.

9. Sutton JR, Reeves JT, Wagner PD, et al. Operation Everest II: oxygen transport during exercise at extreme simulated altitude. J Appl Physiol 1988;64:1309-21.

10. West JB, Schoene B, Milledge JS. High altitude medicine and physiology. London: Arnold, 2007

11. Weil JV, Byrne-Quinn E, Sodal IE, et al. Hypoxic ventilatory drive in normal man. J Clin Invest 1970;49:1061-72.

12. Forster HV, Dempsey JA, Chosy LW. Incomplete compensation of CSF $\left[\mathrm{H}^{+}\right]$in man during acclimatization to high altitude (4800 m). J Appl Physiol 1975;38:1067-72.

13. Pappenheimer JR, Fencl V, SR $\mathrm{H}$, et al. Role of cerebral fluids in control of respiration as studied in unanethetized goats. Am J Physiol 1965;208:436-50.

14. Severinghaus JW, Mitchell RA, Richardson BW, et al. Respiratory control at high altitude suggesting active transport regulation of CSF pH. J Appl Physiol 1963;18:1155-66

15. Grover RF, Bartsch P. Blood. In: Hornbein TF Schoene RB, eds. High altitude: an exploration of human adaptation. New York: Marcel Dekker, 2001.

16. Pugh LGCE. Blood volme and haemoglobin concentration at altitdes above 18,000 ft. (5500 m). J Physiol 1964;170:344-54.

17. Windsor JS, Rodway GW. Heights and haematology: the story of haemoglobin at altitude. Postgrad Med J 2007;83:148-51

18. Huff RL, Lawrence JH, Siri WE, et al. Effects of changes in altitude on hematopoietic activity. Medicine (Baltimore) 1951;30:197-217.

19. Reynafarje C, Lozono R, Valdivieso J. The polycythemia of high altitudes: iron metabolism and related aspects. Blood 1959;14:433-55.

20. Hochachka PW, Stanley C, Merkt J, et al. Metabolic meaning of elevated levels of oxidative enzymes in high altitude adapted animals: an interpretive hypothesis. Respir Physiol 1983;52:303-13.

21. Hoppeler H, Kleinert E, Schlegel C, et al. Morphological adaptations of human skeletal muscle to chronic hypoxia. Int J Sports Med 1990:11 (Suppl 1):S3-9.

22. MacDougall JD, Green HJ, Sutton JR, et al. Operation Everest II: structural adaptations in skeletal muscle in response to extreme simulated altitude. Acta Physiol Scand 1991;142:421-7.

23. Hoppeler $\mathbf{H}$, Vogt M. Muscle tissue adaptations to hypoxia. J Exp Biol 2001:204:3133-9.

24. Howald $\mathbf{H}$, Pette D, Simoneau JA, et al. Effect of chronic hypoxia on muscle enzyme activities. Int J Sports Med 1990:11(Suppl 1):S10-4.

25. Green HJ, Sutton JR, Cymerman A, et al. Operation Everest II: adaptations in human skeletal muscle. J Appl Physiol 1989;66:2454-61.

26. Calbet $\mathbf{J A}$, Boushel $\mathrm{R}$, Radegran $\mathrm{G}$, et al. Why is $\mathrm{VO}_{2}$ max after altitude acclimatization still reduced despite normalization of arterial $\mathrm{O}_{2}$ content? Am J Physiol Regul Integr Comp Physiol 2003:284:R304-16.

27. Hannon JP, Vogel JA. Oxygen transport during early altitude acclimatization: a perspective study. Eur J Appl Physiol Occup Physiol 1977;36:285-97.

28. Oelz 0, Howald H, Di PPE, et al. Physiological profile of world-class high-altitude climbers. J Appl Physiol 1986;60:1734-42.

29. Bartsch P, Grunig E, Hohenhaus E, et al. Assessment of high altitude tolerance in healthy individuals. High Alt Med Biol 2001;2:287-96.

30. King $\mathbf{A B}$, Robinson SM. Ventilation response to hypoxia and acute mountain sickness. Aerosp Med 1972:43:419-21.

31. Moore LG, Harrison GL, McCullough RE, et al. Low acute hypoxic ventilatory response and hypoxic depression in acute altitude sickness. J Appl Physiol 1986:60:1407-12

32. Milledge JS, Beeley JM, Broome J, et al. Acute mountain sickness susceptibility, fitness and hypoxic ventilatory response. Eur Respir J 1991:4:1000-3.

33. Milledge JS, Thomas PS, Beeley JM, et al. Hypoxic ventilatory response and acute mountain sickness. Eur Respir J 1988;1:948-51.

34. West JB. High life: a history of high-altitude physiology and medicine. New York: Oxford University Press, 1998

35. Cerretelli P. Limiting factors to oxygen transport on Mount Everest. J Appl Physio 1976;40:658-67.

36. Pugh LGCE, Gill MB, Lahiri S, et al. Muscular exercise at great altitudes. J Appl Physiol 1964;19:431-40.

37. Adams RP, Welch HG. Oxygen uptake, acid-base status, and performance with varied inspired oxygen fractions. J Appl Physiol 1980:49:863-8. 
38. Erzurum SC, Ghosh S, Janocha AJ, et al. Higher blood flow and circulating NO products offset high-altitude hypoxia among Tibetans. Proc Natl Acad Sci USA 2007; 104:17593-8.

39. Buck LT, Hochachka PW. Anoxic suppression of $\mathrm{Na}(+)-\mathrm{K}(+)-A T P a s e$ and constant membrane potential in hepatocytes: support for channel arrest. Am J Physiol 1993;265:R1020-5

40. Doll C, Hochachka P. Hand S. A microcalorimetric study of turtle cortical slices: insights into brain metabolic depression. J Exp Biol 1994;191:141-53.

41. Hochachka PW, Land SC, Buck LT. Oxygen sensing and signal transduction in metabolic defense against hypoxia: lessons from vertebrate facultative anaerobes. Comp Biochem Physiol A Physiol 1997;118:23-9.

42. Boutilier RG. Mechanisms of cell survival in hypoxia and hypothermia. J Exp Biol 2001;204:3171-81

43. Gnaiger E, Mendez G, Hand SC. High phosphorylation efficiency and depression of uncoupled respiration in mitochondria under hypoxia. Proc Natl Acad Sci USA 2000;97:11080-5.

44. Nedergaard J, Ricquier D, Kozak LP. Uncoupling proteins: current status and therapeutic prospects. EMBO Rep 2005;6:917-21.

45. Semenza GL. HIF-1: mediator of physiological and pathophysiological responses to hypoxia. J Appl Physiol 2000;88:1474-80.

46. Semenza GL, Agani F, Feldser D, et al. Hypoxia, HIF-1, and the pathophysiology of common human diseases. Adv Exp Med Biol 2000;475:123-30.

47. Carmeliet $\mathbf{P}$, Dor Y, Herbert JM, et al. Role of HIF-1alpha in hypoxia-mediated apoptosis, cell proliferation and tumour angiogenesis. Nature 1998;394:485-90.

48. Jung F, Palmer LA, Zhou N, et al. Hypoxic regulation of inducible nitric oxide synthase via hypoxia inducible factor-1 in cardiac myocytes. Circ Res 2000:86:319-25.

49. Palmer LA, Semenza GL, Stoler MH, et al. Hypoxia induces type II NOS gene expression in pulmonary artery endothelial cells via HIF-1. Am J Physiol 1998;274:L212-19.
50. Grocott M, Montgomery $H$, Vercueil A. High-altitude physiology and pathophysiology: implications and relevance for intensive care medicine. Crit Care 2007; 11:203

51. Rivers $\mathbf{E}$, Nguyen B, Havstad S, et al. Early goal-directed therapy in the treatment of severe sepsis and septic shock. N Engl J Med 2001;345:1368-77.

52. Gattinoni L, Brazzi L, Pelosi $P$, et al. A trial of goal-oriented hemodynamic therapy in critically ill patients. Sv02 Collaborative Group. N Engl J Med 1995;333:1025-32.

53. Hayes MA, Timmins AC, Yau EH, et al. Elevation of systemic oxygen delivery in the treatment of critically ill patients. N Engl J Med 1994;330:1717-22.

54. De Backer D, Creteur J, Preiser JC, et al. Microvascular blood flow is altered in patients with sepsis. Am J Respir Crit Care Med 2002;166:98-104.

55. Trzeciak S, Rivers EP. Clinical manifestations of disordered microcirculatory perfusion in severe sepsis. Crit Care 2005;9(Suppl 4):S20-6.

56. Crapo JD. Morphologic changes in pulmonary oxygen toxicity. Annu Rev Physiol 1986;48:721-31.

57. Davis WB, Rennard SI, Bitterman PB, et al. Pulmonary oxygen toxicity. Early reversible changes in human alveolar structures induced by hyperoxia. $N$ Engl J Med 1983;309:878-83.

58. Grocott M, Richardson A, Montgomery $\mathrm{H}$, et al. Caudwell Xtreme Everest: a field study of human adaptation to hypoxia. Crit Care 2007;11:151

\section{ANSWERS}

1. (A) $F(B) F(C) T(D) F(E) F$

(A) $T$ (B) $F(C) F(D) F(E) T$

(A) $T$ (B) $T$ (C) $T$ (D) $T$ (E) $F$

(A) $F(B) F(C) F(D) F(E) F$

5. (A) $T$ (B) $T$ (C) $T$ (D) $F(E) F$ 